\title{
Bilateral Internal Carotid Artery Occlusion as a Cause of Intraventricular Hemorrhage due to Pial Collateral Vessels
}

\author{
Pial Kollateral Damarlara Bağhl Intraventriküler Kanama Nedeni \\ Olarak Bilateral Internal Karotid Arter Oklïzyonu
}

Emine CALISKAN ${ }^{1}$, Yeliz PEKCEVIK ${ }^{1}$, Burak POLAT ${ }^{1}$, Nail OZDEMIR ${ }^{2}$

${ }_{1} \dot{I}_{z m i r}$ Tepecik Training and Research Hospital, Department of Radiology, Izmir, Turkey

${ }^{2} \dot{I}_{z m i r}$ Tepecik Training and Research Hospital, Department of Neurosurgery, Izmir, Turkey

Corresponding Author: Emine CALISKAN / E-mail: eminecaliskanrad@gmail.com

\begin{abstract}
In patients with high-grade atherosclerotic stenosis or occlusion of the extracranial cerebral arteries, subarachnoid hemorrhage (SAH) may occur, potentially due to rupture of fragile dilated pial collateral vessels. This association has been well described in Moyamoya disease. There are only few cases in the literature that reported SAH due to bilateral carotid artery stenosis but intraventricular hemorrhage caused by dilated pial collateral has not been reported yet. We present a case of bilateral carotid artery occlusion presented with intraventricular hemorrhage. Based on the findings in the present case, carotid artery stenosis or occlusion may present with intraventricular hemorrhage due to rupture of the dilated, fragile collateral vessels.
\end{abstract}

KEYWORDS: Angiography, Carotid artery, Computed tomography, Hemorrhage, Intraventricular, Occlusion

öz

Ekstrakraniyal serebral arterlerinde yüksek dereceli aterosklerotik darlık veya oklüzyon olan hastalarda, intrakraniyal bölgede oluşan dilate, frajil, pial kollateral damarlara bağlı subaraknoid kanama (SAK) gelişebilmektedir. Bu birliktelik en iyi olarak Moyamoya hastalığında tariflenmiştir. Hemodinamik stres, frajil kollaterallerde damarsal hasar oluşturup buna bağlı olarak SAK gelişimini tetiklemektedir. Literatürde bilateral internal karotid arter stenozuna bağlı oluşan SAK yalnızca birkaç olguda tanımlanmıştır ancak dilate, frajil kollateral damarlara bağlı oluşan intraventriküler kanama henüz bildirilmemiştir. Mevcut sunulan hastadaki bulgulara dayanarak, karotid arter stenozu veya oklüzyonunda; dilate, frajil, pial kollaterallerin rüptürüne bağlı intraventriküler kanama gelişebileceğini akılda tutmalıyız.

ANAHTAR SÖZCÜKLER: Anjiyografi, Bilgisayarlı tomografi, Hemoraji, İntraventriküler, Karotid arter, Oklüzyon

\section{INTRODUCTION}

Bilateral severe obstruction or occlusion of the extracranial carotid arteries is a hemodynamically critical state. Subarachnoid hemorrhage due to rupture of the dilated fragile pial vessels has been described in patients with Moyamoya disease $(1,2,5)$. There are only a few cases in the literature that report subarachnoid hemorrhage in high-grade atherosclerotic stenosis or occlusion probably due to similar mechanisms as described in Moyamoya disease $(1,3,4)$. However, intraventricular hemorrhage caused by dilated fragile collateral vessels has not been reported previously. We present an unusual case of bilateral carotid artery occlusion that presented with intraventricular hemorrhage probably due to pial collateral vessels.

\section{CASE REPORT}

A 73-year-old man was brought to the emergency department by his relatives due to sudden loss of consciousness at home. The patient had a history of mild hypertension and 40-pack-year of smoking. On admission, he was in state of stupor (Glasgow Coma Scale was E1V3M5). Blood pressure was $160 / 80 \mathrm{mmHg}$, and electrocardiogram showed normal sinus rhythm with mild tachycardia. His temperature, lung and heart auscultation were normal. Laboratory tests, blood chemistry, hemogram and coagulation tests were within normal limits. There was no clinical evidence of endocarditis, with negative findings on blood cultures and a normal finding on transthoracic echocardiogram.

Non-contrast CT scan of the brain revealed isolated intraventricular hemorrhage and mild ventricular dilatation. A chronic right posterior watershed infarct also appreciated (Figure 1). There was no evidence of subarachnoid hemorrhage on cortical sulci or basal cisterns.

Brain CT angiography was obtained with a 64-MDCT scanner (Aquillon 64, Toshiba Medical Systems, Tochigi, Japan) after IV administration of $80 \mathrm{~mL}$ of contrast medium ( $370 \mathrm{mg} \mathrm{l} / \mathrm{mL}$ ). CT 
angiography revealed bilateral occlusion of the internal carotid arteries along with extensive dilated pial collateral vessels (Figures 2; 3A, B). Collateral support via the circle of Willis was weak. The anterior communicating artery was thin and there was no posterior communicating artery. Initial and control CT angiography after 2 weeks demonstrated no evidence of vasculitis, intracranial stenosis, aneurysm or arteriovenous malformation. Pre-contrast and post-contrast images showed no evidence of acute infarction, or an underlying mass. A right frontal external ventricular drain was placed but his condition deteriorated. His condition continued to deteriorate and on the seventeenth day the patient died.

\section{DISCUSSION}

We presented a case of intraventricular hemorrhage associated

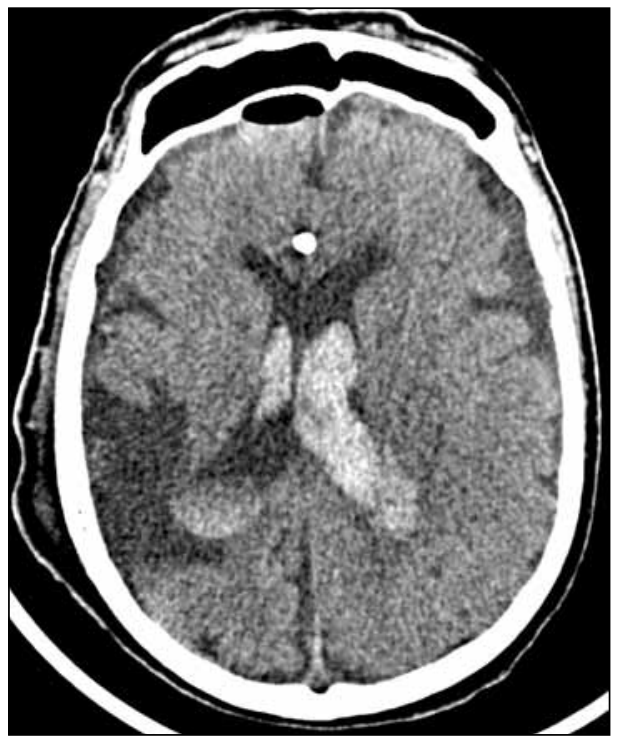

Figure 1: Nonenhanced CT demonstrates intraventricular hemorrhage and mild ventricular dilatation. There is also an old right posterior cortical watershed infarct. with bilateral internal carotid artery occlusion probably due to dilated collateral vessels. Subarachnoid hemorrhage has been described previously but intraventricular hemorrhage associated with bilateral occlusion of the carotid arteries with

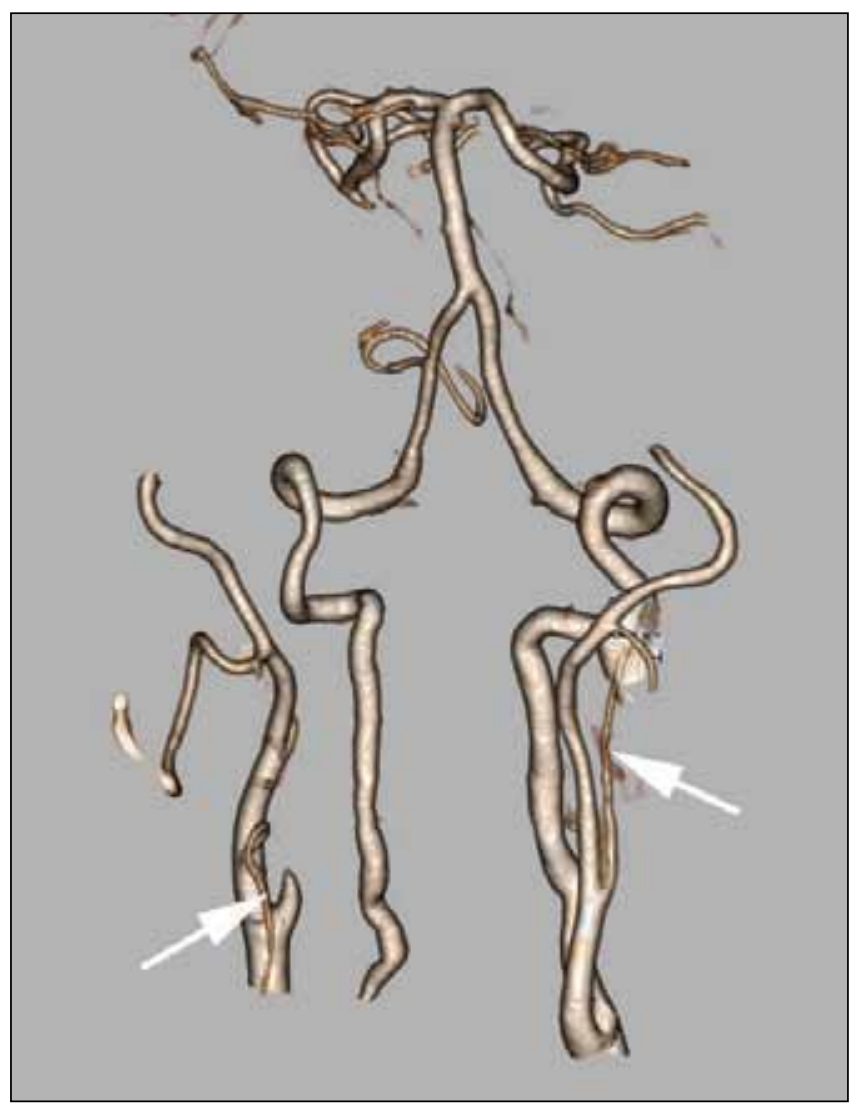

Figure 2: 3D CT angiography, posterior view shows bilateral cervical internal carotid occlusion (arrows).

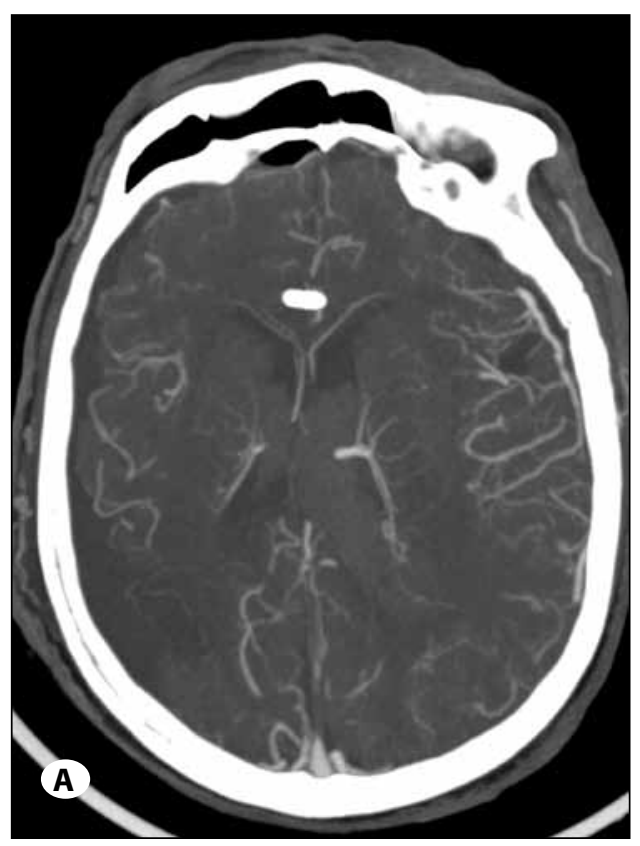

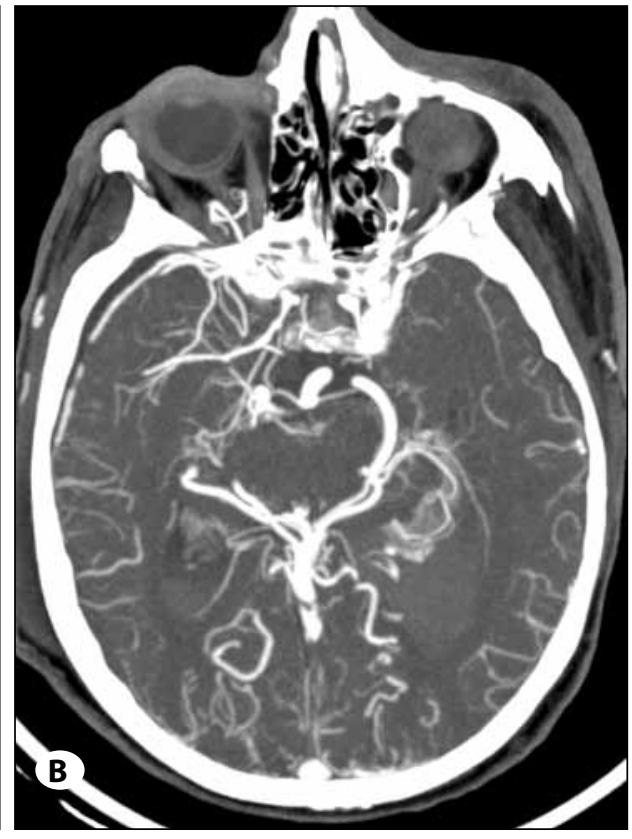

Figure 3A, B: CT angiography, axial maximum intensity projection (MIP) images. Bilateral intracranial segments of the internal carotid arteries, middle and anterior cerebral arteries and its branches are significantly slimmer in appearance. Posterior circulation is prominent. There are extensive dilated collateral vessels in both cerebral hemispheres. 
no appreciated vascular and parenchymal abnormalities has not been reported yet to the best of our knowledge.

Moyamoya is an angiographic finding, characterized by deep and superficial abnormal vascular networks triggered by progressive stenosis or occlusion of the supraclinoid carotid artery $(2,6)$. Most intracranial hemorrhages in Moyamoya occur within the brain are intraparenchymal, subarachnoid or intraventricular and caused by the rupture of associated saccular aneurysms. However, there are few reports of $\mathrm{SAH}$ observed exclusively at the cerebral convexity, which is thought to be caused by the rupture of dilated fragile cortical arterioles. Hemodynamic stress may damage already maximally dilated pial collateral vasculature and produce $\mathrm{SAH}(1,2)$. Similar to the above-described mechanism of SAH observed in Moyamoya, SAH may also occur in high-grade atherosclerotic stenosis of carotid arteries by the rupture of dilated fragile compensatory pial vessels $(1,2)$. In our patient with bilateral internal carotid artery occlusion, there was no evidence of vasculitis, intracranial stenosis, aneurysm, arteriovenous malformation or parenchymal lesion that may cause intraventricular hemorrhage. Although, the etiology of the intraventricular hemorrhage remains uncertain, spontaneous rupture of the dilated fragile collateral vessels is highly probable. The rarity of subarachnoid and intraventricular hemorrhage in the setting of high-grade internal carotid artery stenosis or occlusion may reflect the collateral pathways across the circle of Willis that is usually present. However, the absence of adequate collaterals as in our case may provide a clue to this mechanism of hemorrhage.

\section{CONCLUSION}

In conclusion, in patients with high-grade atherosclerotic stenosis or occlusion of the internal carotid arteries, intraventricular hemorrhage may occur due to rupture of fragile dilated pial collateral vessels. CT angiography evaluation of the subarachnoid and intraventricular hemorrhage should include the cervical vasculature to avoid missing a treatable cause.

\section{REFERENCES}

1. Chandra RV, Leslie-Mazwi TM, Oh D, Mehta B, Yoo AJ: Extracranial internal carotid artery stenosis as a cause of cortical subarachnoid hemorrhage. AJNR Am J Neuroradiol 32: E51-E52, 2011

2. Cuvinciuc V, Viguier A, Calviere L, Raposo N, Larrue V, Cognard C, Bonneville F: Isolated acute nontraumatic cortical subarachnoid hemorrhage. AJNR Am J Neuroradiol 31:13551362, 2010

3. Geraldes R, Santos C, Canhao P: Atraumatic localized convexity subarachnoid hemorrhage associated with acute carotid artery occlusion. Eur J Neurol 2:e28-e29, 2011

4. Kleinig TJ, Kimber TE, Thompson PD: Convexity subarachnoid haemorrhage associated with bilateral internal carotid artery stenoses. J Neurol 256: 669-671, 2009

5. Kumar S, Goddeau RP Jr, Selim MH, Thomas A, Schlaug G, Alhazzani A, Searls DE, Caplan LR: Atraumatic convexal subarachnoid hemorrhage: Clinical presentation, imaging patterns, and etiologies. Neurology 74: 893-899, 2010

6. Osanai T, Kuroda S, Nakayama N, Yamauchi T, Houkin K, Iwasaki Y: Moyamoya disease presenting with subarachnoid hemorrhage localized over the frontal cortex: Case report. Surg Neurol 69: 197-200, 2008 